\title{
BMJ Open Attitudes of doctors and nurses to patient safety and errors in medical practice in the Gaza-Strip: a cross- sectional study
}

\author{
Bettina Bottcher, ${ }^{\oplus 1}$ Nasser Abu-El-Noor, ${ }^{2}$ Yousef Abuowda, ${ }^{1}$ Maha Alfaqawi, ${ }^{1}$ \\ Enas Alaloul, ${ }^{3}$ Somaya El-Hout, ${ }^{3}$ Ibrahem Al-Najjar, ${ }^{1}$ Mysoon Abu-El-Noor ${ }^{2}$
}

To cite: Bottcher $B, A b u-$ El-Noor N, Abuowda Y, et al. Attitudes of doctors and nurses to patient safety and errors in medical practice in the Gaza-Strip: a crosssectional study. BMJ Open 2019;9:e026788. doi:10.1136/ bmjopen-2018-026788

- Prepublication history for this paper is available online. To view these files, please visit the journal online (http://dx.doi. org/10.1136/bmjopen-2018026788).

Received 21 September 2018 Revised 17 June 2019 Accepted 10 July 2019

A) Check for updates

(C) Author(s) (or their employer(s)) 2019. Re-use permitted under CC BY-NC. No commercial re-use. See rights and permissions. Published by BMJ.

${ }^{1}$ Islamic University of Gaza, Faculty of Medicine, Gaza, State of Palestine

${ }^{2}$ Islamic University of Gaza Faculty of Nursing, Gaza, State of Palestine

${ }^{3}$ Palestinian Ministry of Health, Gaza, State of Palestine

Correspondence to Dr Bettina Bottcher; bettina.bottcher@yahoo.co.uk

\section{ABSTRACT:}

Objectives This study examined the attitudes of nurses and doctors to key patient safety concepts, evaluated differences and similarities between professional groups and assessed positive and negative attitudes to identify target areas for future training.

Setting Four major governmental hospitals in the GazaStrip.

Participants A convenience sample of 424 nurses and 150 physicians working for at least 6 months in the study hospitals.

Primary and secondary outcome measures The primary outcome measures were mean scores with SD as measured for individual items and nine main patient safety domains assessed by the Attitudes to Patient Safety Questionnaire. Secondary outcome measures were the proportions of doctors and nurses, that gave a positive response to each item, represented as percentage of each group.

Results Nurses and doctors held moderately positive attitudes towards patient safety with five out of nine domain scores $>3.5$ of 5 . Doctors showed slightly more positive attitudes than nurses, despite a smaller proportion of doctors having received patient safety training with $37.5 \%$ compared with $41.9 \%$ of nurses. Both professions displayed their most positive patient safety attitudes in the same domains ('team functioning' and 'working hours as a cause for error'), as well as their two most negative attitudes ('importance of patient safety in the curriculum' and 'professional incompetence as a cause of error'), demonstrating significant deficits in understanding medical errors. A specific challenge will be the negative attitudes of both professions towards patient safety training for wider dissemination of this content in the postgraduate curriculum.

Conclusion Patient safety attitudes were moderately positive in both professional groups. Target of future patient safety training should be enhancing the understanding of error in medicine. Any training has to be motivating and relevant for clinicians, demonstrating its importance in ongoing professional learning.

\section{BACKGROUND}

In hospitals, one out of 150 patients have been reported to die as a consequence of an adverse event. ${ }^{1}$ Positive patient safety attitudes
Strengths and limitations of this study

- Recruitment of a large and diverse sample from different governmental hospitals and areas in the Gaza-Strip, including $56.3 \%$ of the target population is a strong point in this study, as well as the assessment of patient safety attitudes in different professions.

- Another strength is the low proportion of missing values, which may be due to face-to-face distribution and collection of questionnaires by members of the research team, as well as an urge of professionals to share their views.

- A limitation of the study is the use of a convenience sample, which might limit generalisability of the findings.

- Further limitations include the fact that the Attitudes to Patient Safety Questionnaire (APSQ-III) used in this study was originally designed for medical students and that it does not enable direct comparison with other studies in this area, which used other questionnaires that assess patient safety attitudes in institutional/workplace contexts.

- However, the advantage of the APSQ-III in the context of this study, over other survey instruments, was that it examines healthcare professionals' attitudes and does not focus on organisational culture, allowing the comparison of different professional groups working across Gaza in different hospitals.

are associated with better patient outcomes as well as conversely, negative attitudes with poorer patient outcomes. ${ }^{2}$ Furthermore, patient safety training and education can improve patient safety attitudes and thus also patient outcomes, creating a safer healthcare environment for patients. ${ }^{145}$ Moreover, patient safety attitudes have been shown to be associated with staff well-being, bullying in the workplace, quality of delivered care and job satisfaction. ${ }^{6-9}$ Thus, patient safety has a wide reaching influence on professionals' and patients' experiences in healthcare 
systems. Healthcare professionals with positive attitudes towards patient safety are more likely to display patient safety-related behaviours. ${ }^{1011}$

A survey using the Global Trigger Tool found that one in seven patients admitted to Palestinian hospitals suffered from harm and $59.3 \%$ of these had been preventable,${ }^{12}$ thus compounding the difficult situation with staff and equipment shortages and contributing to poor patient outcomes. Furthermore, adverse events were shown to be significantly associated with poor safety culture in two hospitals in the West Bank, Palestine. ${ }^{13}$ Therefore, improving patient safety attitudes and awareness among staff may contribute significantly to better patient outcomes in Palestine at little additional costs. ${ }^{14513}$ Simple changes in staff behaviour, such as in infection control practices, have been shown to be achievable and can positively affect patient care. ${ }^{14}$ But increased awareness of their significance and a culture of such practice has yet to be created. ${ }^{15-17}$ Some improvements have already been achieved to increase patient safety standards in Palestinian hospitals by efforts introducing the Patient Friendly Initiative to West Bank hospitals. ${ }^{18}$

Although patient safety education has been integrated in many postgraduate curricula across the world, it only has a small presence in postgraduate education in Gaza. ${ }^{19-22}$ Therefore, it is not surprising that patient safety attitudes among local healthcare professionals appear to be lagging behind that of regional and international colleagues. ${ }^{22-27}$ This study assessed patient safety attitudes among doctors and nurses working at governmental hospitals in the Gaza-Strip and examined differences and similarities, as well as positive and negative attitudes in order to identify areas for future training.

\section{METHODS}

A descriptive, cross-sectional study, using a self-administered questionnaire was conducted in four major governmental hospitals that represent the governorates of the Gaza-Strip. A convenience sample of 600 doctors and nurses was recruited by personal invitation to participate in this study. The total numbers of employed doctors and nurses in all four study hospitals are 375 doctors and 645 nurses, resulting in a total study population of 1020. Professionals were eligible to participate if they had worked at one of the four governmental hospitals for at least 6 months prior to participating in this study. The data were collected by members of the research team who were not working in the governmental health system. Eligible participants were approached at their workplace, the purpose of the survey was explained to them and those, who agreed to participate, were handed the questionnaire by a research team member. Each participant completed the questionnaire alone and anonymously. The survey instrument used was the Attitudes to Patient Safety Questionnaire III (APSQ-III) ${ }^{28}$ This had been translated into Arabic by three different healthcare professionals fluent in both English and Arabic and with experience in health research and survey design. This translation was back-translated from Arabic to English by two other bilingual healthcare professionals, ensuring consistency. Face validity was assessed by faculty members of local faculties of nursing and medicine, all of them experienced nurses and doctors, who reviewed the questionnaire and suggested slight modifications to better address local healthcare personnel, resulting in a 30-item questionnaire. Finally, this Arabic version of the questionnaire was completed by 20 experienced doctors and nurses from the study hospitals, who were not included in the study. The reliability of the instrument was assessed with Cronbach's $\alpha$, which was 0.71 showing acceptable reliability.

The APSQ-III examines patient safety attitudes over nine domains; patient safety training received, error reporting confidence, working hours as an error cause, error inevitability, professional incompetence as an error cause, disclosure responsibility, team functioning, patient involvement to reduce error and importance of patient safety training. It had originally been developed for use in medical students with the intent to be used in a wider context. ${ }^{28}$ Its advantage in the context of this study over other survey instruments was that it examines healthcare professionals' attitudes and does not focus on organisational culture, allowing the comparison of different professional groups working across Gaza in different hospitals.

Responses to each item were rated on a 5-point Likert scale ranging from 1 (strongly disagree) to 5 (strongly agree). A higher score indicated a more affirmative or positive attitude; a score of 3 reflected a neutral attitude and scores below 3 showed negative attitudes. Several items had a reverse score, according to the instructions of the original creators of the instrument. ${ }^{28}$ Each participant's response was summed up into nine subscores that corresponded to the nine key domains.

\section{Data analysis}

All statistical analyses were performed using the Statistical Package for the Social Sciences for Windows V.22.0. The results are given in means $\pm \mathrm{SD}$ as well as percentage of positive responses to each item among each professional group. Significance was tested by the independent sample t-test for participants' characteristics and item scores. Although the use of parametric tests with Likert scales remains controversial, as this is an ordinal scale, it has been shown to be more robust than non-parametric tests, especially in large samples, as in this study. ${ }^{29}{ }^{30}$ Assumptions for t-tests were tested and not violated. A p-value of $\leq 0.05$ was considered statistically significant.

\section{Patient and public involvement}

Patients or community members have not been involved in the design or conduct of this study. 


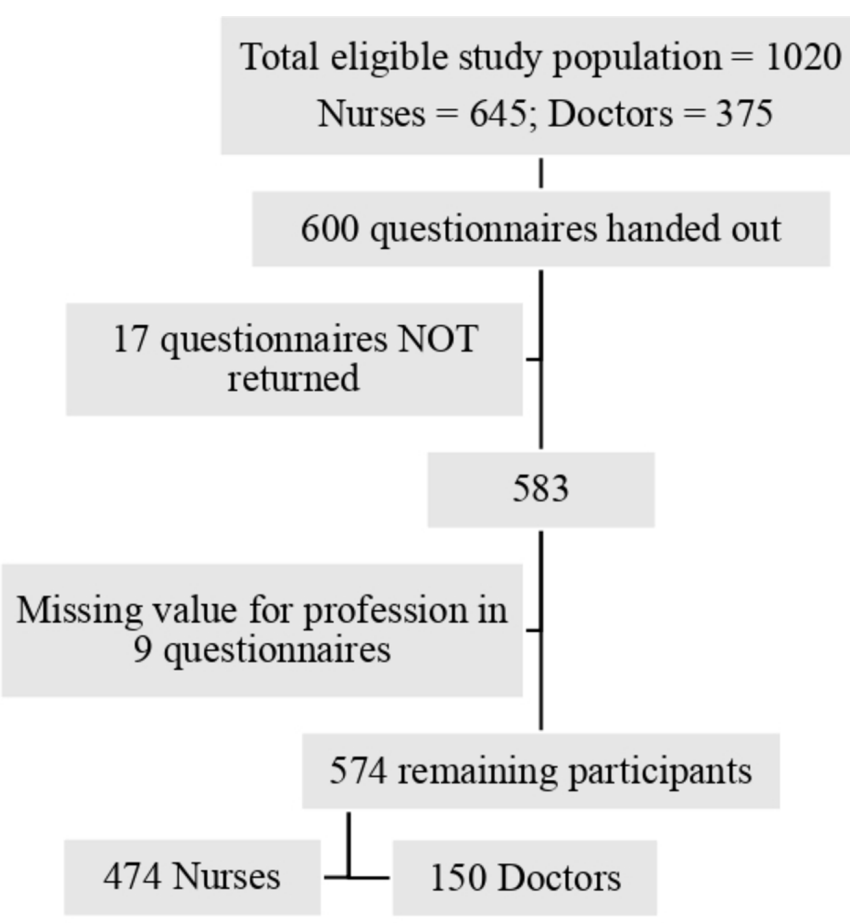

Figure 1 Study population flow chart.

\section{RESULTS}

In total 645 nurses and 375 doctors were working in the study hospitals, of which 600 were given a copy of the APSQ-III to complete. From these, 583 professionals completed and returned the questionnaire to a research team member. The information if the participant was a doctor or a nurse was missing in nine questionnaires. Therefore, these were excluded from the study, leaving 424 nurses $(65.7 \%$ of all nurses) and 150 (40.0\% of all doctors) doctors included in the study (figure 1).

The number of total missing values was low with 296 unanswered questions out of $17220(1.6 \%)$ in the $574 \times 30$ item questionnaire. These were randomly distributed among all items, ranging from 2 of 574 unanswered questions $(0.3 \%)$ to $33(5.6 \%)$. Missing values were replaced by the mean for each item, for calculation of the mean score.

\section{Characteristics of participants}

Participants' mean age was 33.1 \pm 9.2 years for nurses and $36.6 \pm 9.8$ for doctors (table 1 ). No significant differences were found between the two professional groups in their work experience or the hours of patient safety training they had received previous to filling out the questionnaire (table 1). However, the proportion of participants who had benefited from patient safety education was higher among the nurses with $56.2 \% \quad(n=247 / 425)$ reporting not to have received any patient safety education, compared with $61.3 \% \quad(n=92 / 150)$ of doctors (table 1).

\section{Similarities in patient safety attitudes of doctors and nurses}

Doctors and nurses gave similar responses in 14 individual items of the APSQ-III (table 2) as well as four of nine patient safety domains tested by the APSQ-III (table 2). Interestingly, both professional groups shared their most negative and most positive attitudes in individual item as well as patient safety domain scores (table 2 ).

\section{Differences in patient safety attitudes of doctors and nurses}

Significant differences were found in 16 individual items of the APSQ-III between doctors and nurses (table 2) as well as five of nine patient safety domains tested in the APSQ-III. Doctors displayed more positive attitudes in the domains of patient safety training received, working hours as a cause of error and professional incompetence as a cause of error, while nurses held more positive attitudes in error reporting confidence and error inevitability (table 2). Reflecting the difference of error reporting confidence, $31.1 \%$ of doctors gave a positive response to the reversely coded item 'I don't think I make errors', which meant in this context that $31.1 \%$ of doctors acknowledged to make mistakes, compared with $52.4 \%$ of nurses. Furthermore, $28.7 \%$ of doctors found disclosure of errors mandatory in all cases (by giving a positive response to the reversely coded item 'Doctors/ nurses have a responsibility to disclose errors to patients only if they result in patient harm') compared with $34.7 \%$ of nurses (table 2).

\begin{tabular}{|c|c|c|c|c|c|}
\hline & \multicolumn{2}{|c|}{ Doctors $(n=150)$} & \multicolumn{2}{|c|}{ Nurses $(n=424)$} & P-value \\
\hline Age in years & \multicolumn{2}{|l|}{$36.6 \pm 9.8$} & \multicolumn{2}{|l|}{$33.1 \pm 9.2$} & $<0.001$ \\
\hline Work experience in years & \multicolumn{2}{|l|}{$9.5 \pm 8.2$} & \multicolumn{2}{|l|}{$9.4 \pm 7.8$} & 0.954 \\
\hline Previous patient safety training in hours & \multicolumn{2}{|l|}{$7.4 \pm 15.8$} & \multicolumn{2}{|l|}{$7.7 \pm 21.8$} & 0.828 \\
\hline Median & \multicolumn{2}{|l|}{0} & \multicolumn{2}{|l|}{0} & \\
\hline Range & \multicolumn{2}{|l|}{$0-100$} & \multicolumn{2}{|l|}{$0-200$} & \\
\hline Previous patient safety training received & Yes & No & Yes & No & \\
\hline Number & 56 & 92 & 177 & 247 & \\
\hline Percentage & $37.30 \%$ & $61.30 \%$ & $41.90 \%$ & $56.20 \%$ & $<0.001$ \\
\hline Missing & & 2 & & 8 & \\
\hline
\end{tabular}


Table 2 Results for individual items in each domain as means \pm SD, percentage of positive responses to each item and $\mathrm{p}$-value for differences between professions

1. Patient safety training received

\begin{tabular}{|c|c|c|c|c|c|}
\hline & \multicolumn{2}{|c|}{ Doctors $(n=150)$} & \multicolumn{2}{|c|}{ Nurses ( $n=424)$} & \multirow[b]{2}{*}{ P-value } \\
\hline & $\begin{array}{l}\text { Means } \pm \\
\text { SD }\end{array}$ & $\begin{array}{l}\% \text { of positive } \\
\text { response }\end{array}$ & $\begin{array}{l}\text { Means } \pm \\
\text { SD }\end{array}$ & $\begin{array}{l}\% \text { of positive } \\
\text { response }\end{array}$ & \\
\hline My training has prepared me & $3.3 \pm 1.0$ & 47.2 & $3.4 \pm 1.2$ & 54.7 & 0.082 \\
\hline
\end{tabular}

to understand the causes of medical errors.

2. Error reporting confidence
I would feel comfortable
reporting any errors I had
made no matter how serious
the outcome had been for the
patient.

I would feel comfortable

$3.1 \pm 1.1$

$3.5 \pm 1.0$

57.3

$<0.001^{\star}$

reporting any errors other people had made, no matter how serious the outcome had been for the patient.

I feel confident I could report an error I had made without feeling I would be blamed.

I am confident I could talk openly to my supervisor about an error I had made if it had resulted in potential or actual harm to my patient.

Medical errors are handled

35.5

$3.3 \pm 1.1$

48.3

$0.001^{*}$

appropriately in my workplace.

\begin{tabular}{|c|c|c|c|c|c|}
\hline $\begin{array}{l}\text { 3. Working hours as a cause of } \\
\text { errors }\end{array}$ & $4.2 \pm 0.7$ & & $3.9 \pm 0.8$ & & $<0.001^{*}$ \\
\hline $\begin{array}{l}\text { The number of hours doctors/ } \\
\text { nurses work increases the } \\
\text { likelihood of making medical } \\
\text { errors. }\end{array}$ & $4.2 \pm 1.0$ & 70.6 & $3.9 \pm 1.2$ & 66.0 & $0.003^{*}$ \\
\hline $\begin{array}{l}\text { Shorter shifts will reduce } \\
\text { medical errors. }\end{array}$ & $4.1 \pm 1.0$ & 78.7 & $3.9 \pm 1.1$ & 66.7 & $0.016^{*}$ \\
\hline I like my job. & $4.1 \pm 0.9$ & 80.7 & $4.0 \pm 1.0$ & 76.4 & 0.205 \\
\hline 4. Error inevitability & $3.7 \pm 0.6$ & & $3.9 \pm 0.6$ & & $0.033^{*}$ \\
\hline I do not think I make errors. (R) & $2.9 \pm 1.1$ & 31.3 & $3.4 \pm 1.1$ & 52.4 & $<0.001^{*}$ \\
\hline
\end{tabular}

competent nurses make errors.

\begin{tabular}{|c|c|c|c|c|c|}
\hline $\begin{array}{l}\text { 5. Professional incompetence as } \\
\text { a cause of error }\end{array}$ & $3.3 \pm 0.5$ & & $3.1 \pm 0.6$ & & $<0.001^{*}$ \\
\hline $\begin{array}{l}\text { A true professional does not } \\
\text { make mistakes or errors. }(R)\end{array}$ & $3.9 \pm 1.1$ & 74.0 & $3.6 \pm 1.1$ & 60.1 & $0.006^{*}$ \\
\hline $\begin{array}{l}\text { Most medical errors result from } \\
\text { careless nurses. }(\mathrm{R})\end{array}$ & $3.4 \pm 0.9$ & 50.7 & $3.6 \pm 1.3$ & 56.6 & 0.051 \\
\hline
\end{tabular}




\section{Table 2 Continued}

1. Patient safety training received

\begin{tabular}{|c|c|c|c|c|c|}
\hline & \multicolumn{2}{|c|}{ Doctors $(n=150)$} & \multicolumn{2}{|c|}{ Nurses $(n=424)$} & \multirow[b]{2}{*}{ P-value } \\
\hline & $\begin{array}{l}\text { Means } \pm \\
\text { SD }\end{array}$ & $\begin{array}{l}\% \text { of positive } \\
\text { response }\end{array}$ & $\begin{array}{l}\text { Means } \pm \\
\text { SD }\end{array}$ & $\begin{array}{l}\% \text { of positive } \\
\text { response }\end{array}$ & \\
\hline $\begin{array}{l}\text { Most medical errors result from } \\
\text { careless doctors. }(R)\end{array}$ & $3.3 \pm 1.2$ & 46.7 & $2.7 \pm 1.1$ & 24.1 & $<0.001^{*}$ \\
\hline 6. Disclosure responsibility & $3.5 \pm 0.6$ & & $3.5 \pm 0.6$ & & $<0.711$ \\
\hline $\begin{array}{l}\text { Doctors/nurses have a } \\
\text { responsibility to disclose errors } \\
\text { to patients only if they result in } \\
\text { patient harm. }\end{array}$ & $2.8 \pm 1.1$ & 28.7 & $3.0 \pm 1.1$ & 34.7 & 0.139 \\
\hline $\begin{array}{l}\text { All medical errors should be } \\
\text { reported. }\end{array}$ & $3.9 \pm 0.9$ & 68.7 & $3.9 \pm 1.0$ & 72.6 & 0.931 \\
\hline It is not necessary to report & $3.4 \pm 1.1$ & 47.6 & $3.2 \pm 1.2$ & 43.6 & 0.060 \\
\hline
\end{tabular}
errors which do not result in adverse outcomes for the patient. (R)

It is the responsibility of all

formally report all medical errors which occur.

\begin{tabular}{|c|c|c|c|c|c|}
\hline 7. Team functioning & $3.9 \pm 0.6$ & & $3.9 \pm 0.6$ & & 0.914 \\
\hline $\begin{array}{l}\text { Better multidisciplinary } \\
\text { teamwork will reduce medical } \\
\text { errors. }\end{array}$ & $4.3 \pm 0.9$ & 86.7 & $4.1 \pm 0.8$ & 82.2 & $0.017^{\star}$ \\
\hline $\begin{array}{l}\text { 8. Patient involvement in } \\
\text { reducing error }\end{array}$ & $3.5 \pm 0.8$ & & $3.5 \pm 0.6$ & & 0.958 \\
\hline $\begin{array}{l}\text { Patients have an important role } \\
\text { in preventing medical errors. }\end{array}$ & $3.4 \pm 1.0$ & 53.3 & $3.6 \pm 1.0$ & 59.2 & 0.082 \\
\hline $\begin{array}{l}\text { Encouraging patients to be more } \\
\text { involved in their care can help to } \\
\text { reduce the risk of medical errors } \\
\text { occurring. }\end{array}$ & $4.0 \pm 0.8$ & 84.0 & $3.9 \pm 0.9$ & 74.3 & $0.047^{\star}$ \\
\hline $\begin{array}{l}\text { Patient safety issues cannot be } \\
\text { taught and can only be learnt } \\
\text { by clinical experience when } \\
\text { qualified. (R) }\end{array}$ & $3.6 \pm 1.1$ & 57.3 & $3.2 \pm 1.2$ & 42.0 & $<0.001^{*}$ \\
\hline $\begin{array}{l}\text { Learning about patient safety } \\
\text { issues before I qualify will help } \\
\text { me to become a more effective } \\
\text { doctor/nurse. }\end{array}$ & $3.9 \pm 1.0$ & 74.0 & $3.8 \pm 0.9$ & 71.7 & 0.858 \\
\hline $\begin{array}{l}\text { Learning about patient safety } \\
\text { issues is not as important as } \\
\text { learning other more skill based } \\
\text { aspects of being a doctor/a } \\
\text { nurse. (R) }\end{array}$ & $2.3 \pm 1.1$ & 16.7 & $2.7 \pm 1.2$ & 25.7 & $0.001^{*}$ \\
\hline
\end{tabular}

The darkly shaded rows show results for patient safety domain scores as means \pm SD.

*Statistically significant, (R) reversely coded items.

Positive and negative patient safety attitudes

Very positive attitudes were found in participants of both professional groups (mean $>4$ ) on the items 'Even the most experienced and competent doctors make errors', 'Even the most experienced and competent nurses make errors' and 'Better multidisciplinary teamwork will reduce medical 
errors' with $>80 \%$ of participants giving a positive response. This was also demonstrated in the most positive attitudes of both professional groups in the patient safety domains 'Working hours as a cause of error' as well as 'Professional incompetence as a cause of errors' (table 2).

Additionally, doctors had very positive attitudes on the items 'Teaching teamwork skills will reduce medical error', 'Encouraging patients to be more involved in their care can help to reduce the risk of medical errors occurring', 'Shorter shifts will reduce medical errors', 'By not taking regular breaks during shifts doctors/nurses are at an increased risk of making errors' and 'I like my job'. While the participating nurses had no other item with a positive response rate of $>80 \%$ of participants. (table 2 ).

Negative patient safety attitudes were displayed by both professional groups on the item 'Learning about patient safety issues is not as important as learning other more skill based aspects of being a doctor/a nurse', also reflected by the lowest patient safety attitudes held in both professions on the patient safety domain of 'Importance of patient safety in the curriculum'. However, the lowest score by far was achieved for the item 'If people paid more attention at work, medical errors would be avoided' with less than $8 \%$ of participants in both professions holding a positive attitude (table 2).

\section{DISCUSSION}

In general, doctors showed more positive attitudes towards patient safety than nurses who participated in this study, although significantly more nurses had received patient safety training than doctors, but conversely doctors displayed a significantly more positive attitude towards the patient safety training they had received (tables 1 and 2). Both professional groups showed their most negative as well as their most positive attitudes in the same domains and on the same items, which is in contrast to some international studies on patient safety attitudes including doctors and nurses, ${ }^{31-33}$ but similar to a recent study from Palestine. ${ }^{18}$ However, significant differences between both professional groups were found on the majority of items (16 of 30 item) and domains (five out of nine domains), with nurses having significantly more positive attitudes in the domains of 'Error reporting confidence' and 'Error inevitability' and doctors in 'Working hours as a cause of error' and 'Professional incompetence as a cause of error'.

\section{Team functioning}

Good functioning of the team has been recognised as one of the most important factors in securing patient safety and establishing a safe patient culture. ${ }^{21}$ Leonard et al investigated 2455 sentinel events reported to the Commission on Accreditation of Healthcare Organizations and found that $70 \%$ of these were due to a breakdown in the team functioning. ${ }^{34}$ Teamwork also gathered the most positive attitudes in different studies in other contexts, as among nurses in Iran,$^{35}$ operating department teams in Sweden, ${ }^{32}$ medical students in Taiwan ${ }^{26}$ and Pakistan ${ }^{33}$ or medical interns in Korea. ${ }^{36}$ Physicians and nurses in Gaza showed more positive attitudes towards team work than nurses in Lithuania ${ }^{31}$ or medical students in Hong Kong and Singapore. ${ }^{19}$ One reason for the positive attitudes in this study might be a recent emergence of undergraduate and postgraduate team training in the local context, such as in trauma care, resuscitation teams or unit teams. ${ }^{14}$

Teams act in different forms in healthcare, including short-term teams, such as resuscitation teams, more stable teams, such as those working together on one shift or long-term teams in one unit. Several definitions of teams have been discussed, but they all have common factors, including shared identity, clear roles/goals, shared responsibility, interdependence of team members, integration of work and team tasks. ${ }^{37-40}$ The importance of these factors varies with types of teams and their purpose. Teamwork requires varying levels of collaboration, coordination, cooperation, networking or a mixture of these types of teamwork. ${ }^{3841}$ Healthcare workers will be part of different teams in their career. Although participants of this study were recruited from different specialities and departments, they displayed agreement on the importance of efficient teamwork to ensure patient safety, demonstrating commonly shared and agreed values towards this important factor. This offers potential to be translated into a culture of shared values when they work together in one unit. ${ }^{32}{ }^{42}$ However, the actual teamwork climate in Palestinian hospitals is lagging behind this attitude demonstrated by doctors and nurses. Within the Arab context, a systematic review by Elmontsri et al, which included a Palestinian study, examined patient safety culture within hospital units and found actual team work culture was rated better within units $(71 \%$ in the Palestinian study) than across hospitals (44\% in Palestine) and this was worse than in most studies from other Arab countries. ${ }^{25}$ Therefore, to improve efficiency of teams, training has to address existing teams as well as individuals, who will use their skills in different team contexts. ${ }^{1437-394143}$

\section{Working schedule}

The working hours received the second highest patient safety ratings in both professions with doctors' attitudes significantly more positive than nurses. Heavy workload, poor staffing levels and unsatisfactory facilities have been identified as challenges to the provision of safe care in Gaza Hospitals in other studies. ${ }^{5} 23445$ In times of crises, such pressures are often further exacerbated. Therefore, it is safe to assume that both doctors and nurses have experienced excessive working hours and workload before and are able to judge the effect this might have on patient safety based on their own experiences. Although this factor is important to ensure patient safety, ${ }^{67}$ it is often neglected in low resource settings, as experienced by participants of this study. ${ }^{20}$

\section{Understanding and dealing with medical error}

A main threat to patients are medical errors that have been reported to be the third leading cause of death 
in the $\mathrm{USA}^{46}$ and affect one in seven patients admitted to Palestinian hospitals. ${ }^{12}$ Therefore, one of the most important concepts in patient safety is the causation of and learning from errors. This includes the understanding that errors are often not individual failings, but system failures, which can be of vital importance for an organisation to learn and develop systems that keep patients safer in the future. ${ }^{46}{ }^{47}$ It is vital that individual professionals, teams as well as managers and organisations use such opportunities for improvement of safe patient management.

One component of this is the realisation that errors are inevitable,${ }^{47}$ but it is the responsibility of a well-designed system to prevent them causing actual harm to patients. In this study, the professional groups displayed positive attitudes in the domain 'Error inevitability' with nurses having higher scores than doctors and showing a degree of understanding of human factors and their contribution to possible errors. Conversely, however, in the domain 'Professional incompetence as a cause of error' nurses showed the most negative and doctors the second most negative attitudes, demonstrating deficient understanding in this area. One reason for this can be the relatively small proportion of participants who had received patient safety training. Another factor might be the experience of participants of how management and the Palestinian Ministry of Health deal with mistakes in practice, showing also poor understanding of this concept. In one study in Palestine, 34.5\% of participants reported difficulties in discussing and learning from error, confirming a cultural problem in this area affecting a large proportion of healthcare professionals. ${ }^{5}$ Similarly, in a report investigating maternal mortality in the Gaza-Strip, clinicians reported that they felt unsupported by management in case of adverse events. ${ }^{48}$ However, similar discrepancies between the acknowledgement that errors are inevitable, but that professionals should not make mistakes were also found internationally, ${ }^{28} 3133354950$ possibly reflecting the ideal for professionals not to make mistakes. The understanding of this discrepancy, between error inevitability and the ideal of professionals avoiding them, needs to be focused on in further training as well as by developing more effective systems to deal with errors openly and learn from them. ${ }^{51} 52$

Doctors held significantly more negative attitudes in 'Error reporting confidence' than nurses, possibly reflecting disparate cultures in this domain within both professions. However, 'Disclosure responsibility' showed no significant differences, reflecting general poor understanding of incident reporting and analysis as a tool of learning. Similar findings were shown in other studies in the Palestinian and wider Arab context, as well as other countries. ${ }^{5234853}$ In order to achieve ongoing organisational learning and continuous improvement in care, a disclosure system and disclosure training for professionals are essential to facilitate learning from mistakes. Both are absent locally and the impact of this deficiency on patient safety attitudes is demonstrated by this study. ${ }^{52}$

\section{Patient safety education}

It has been acknowledged widely that patient safety is an important component of the undergraduate as well as postgraduate curricula. ${ }^{54-56}$ However, neither nurses nor doctors, participating in this study, found training in patient safety particularly important for healthcare professionals. This could be due to the 'hidden curriculum' that has been discussed by several researchers, ${ }^{5758}$ describing the fact that students and professionals witness behaviours in clinical practice, possibly on a daily basis, which are contradicting their learning. Healthcare professionals might feel demotivated and therefore find that patient safety training has no value.

This is a big challenge to overcome, as only the motivated students might have full benefit from any delivered teaching. ${ }^{59}$ Therefore, delivering patient safety training should be regarded as a priority and use novel ways of its teaching in order to keep a close link to clinical practice as well as capture the learners' imagination and interest. Numerous different ways have been investigated and described, including simulation training, e-learning, problem-based learning, self-reflection, critical thinking and even an iPad game. ${ }^{60-64}$ Developing such curriculum content requires leadership, resources and commitment, which can be difficult to mobilise, especially in the context of low-income and middle-income countries like Palestine who have many other challenges to cope with. ${ }^{20}$ A study examining the impact of patient safety interventions undertaken in Palestinian hospitals by several bodies, including the WHO and the Patient Friendly Hospitals Initiative showed a $9.1 \%$ improvement in patient safety attitudes of healthcare staff in the area with the largest improvement, which was incidence reporting frequency. Despite the fact that a large volume of monies was spent on this improvement over a 3-year period from 2011 to 2014, it only achieved a moderate impact. ${ }^{18}$ This finding underlines the significance of identifying those interventions with the greatest effect, in order to ensure not only impact, but also cost effectiveness. Nonetheless, such investment might in the future pay off in terms of improved patient outcomes and a more satisfied workforce.

\section{CONCLUSION}

Nurses and doctors displayed their most positive patient safety attitudes in the same domains ("importance of teamwork' and 'working hours as a cause for error") as well as their most negative attitudes ("importance of patient safety training' and 'professional incompetence as a cause for error'). However, differences were also found with nurses being more confident in error reporting and doctors having slightly better understanding of possible causes of error, such as working hours. Healthcare policy-makers and educators have to focus on the delivery of patient safety training, which is both motivating and relevant for clinicians and demonstrates the importance of this content in ongoing professional learning. Furthermore, inevitability of medical errors, their impact and 
learning from them are an essential part of undergraduate as well as postgraduate training and have to be more consistently included in curriculum delivery.

Contributors BB designed the study, performed the statistical analysis, contributed to and supervised data collection, contributed to interpretation of results, drafted and revised the manuscript. NAEN and MAEN contributed to the design of the study and the statistical analysis as well as interpretation of results and contributed to revision of the manuscript. YA and MA contributed substantially to the data collection, supervised the process of data collection and data entry, participated in interpretation of results and statistical analysis and revision of the manuscript. EA, SEH and IAN conducted the data collection and supported interpretation of results and revision of the manuscript.

Funding The authors have not declared a specific grant for this research from any funding agency in the public, commercial or not-for-profit sectors.

Competing interests No, there are no competing interests for any author.

Patient and public involvement statement Not required.

Ethics approval Approval was received from the ethics committee of the Human Resources Department of the Palestinian Ministry of Health. Formal written consent was obtained from all participants in this study. All data were kept completely anonymously.

Provenance and peer review Not commissioned; externally peer reviewed.

Data availability statement All available data is represented in this text.

Open access This is an open access article distributed in accordance with the Creative Commons Attribution Non Commercial (CC BY-NC 4.0) license, which permits others to distribute, remix, adapt, build upon this work non-commercially, and license their derivative works on different terms, provided the original work is properly cited, appropriate credit is given, any changes made indicated, and the use is non-commercial. See: http://creativecommons.org/licenses/by-nc/4.0/.

\section{REFERENCES}

1. de Vries EN, Ramrattan MA, Smorenburg SM, et al. The incidence and nature of in-hospital adverse events: a systematic review. Qual Saf Health Care 2008;17:216-23.

2. DiCuccio $\mathrm{MH}$. The relationship between patient safety culture and patient outcomes: a systematic review. J Patient Saf 2015;11:135-42.

3. Singer S, Lin S, Falwell A, et al. Relationship of safety climate and safety performance in hospitals. Health Serv Res 2009;44:399-421.

4. de Vries EN, Prins HA, Crolla RMPH, et al. Effect of a comprehensive surgical safety system on patient outcomes. $N$ Engl J Med 2010;363:1928-37.

5. Elsous A, Akbari Sari A, Rashidian A, et al. A cross-sectional study to assess the patient safety culture in the Palestinian hospitals: a baseline assessment for quality improvement. JRSM Open 2016;7.

6. Taylor JA, Dominici F, Agnew J, et al. Do nurse and patient injuries share common antecedents? an analysis of associations with safety climate and working conditions. BMJ Qual Saf 2012;21:101-11.

7. Lin Y, Hsiao S, Lin C, et al. Exploration of the association between workplace bullying and attitudes toward patient safety in female nurses. Hu Li Za Zhi The J of Nurs 2018;65:51-60.

8. Merino-Plaza M, Carrera-Hueso F, Roca-Castelló M, et al. Relationship between job satisfaction and patient safety culture. Gan Sanit 2017.

9. Mahrous MS. Patient safety culture as a quality indicator for a safe health system: experience from Almadinah Almunawwarah, KSA. J Taibah Univ Med Sci 2018;13:377-83.

10. Neal A, Griffin MA. A study of the lagged relationships among safety climate, safety motivation, safety behavior, and accidents at the individual and group levels. J Appl Psychol 2006;91:946-53.

11. El-Jardali F, Dimassi H, Jamal D, et al. Predictors and outcomes of patient safety culture in hospitals. BMC Health Serv Res 2011;11:45.

12. Najjar S, Hamdan M, Euwema MC, et al. The global trigger tool shows that one out of seven patients suffers harm in Palestinian hospitals: challenges for launching a strategic safety plan. Int J Qual Health Care 2013;25:640-7.

13. Najjar S, Nafouri N, Vanhaecht K, et al. Improving patient safety in Palestinian hospitals: a cross-sectional and retrospective chart review study. The Lancet 2018;391.

14. Alrumi N, Aghaalkurdi M, Habib H, et al. Infection control measures in neonatal units: implementation of change in the Gaza-Strip. J Matern Fetal Neonatal Med 2019:1-7.
15. Abukhalil M, Bottcher B, Mehjez O, et al. Medical records of emergency caesarean sections in the Gaza strip: a clinical audit. The Lancet 2018;391.

16. Elshami M, Dabbour R, Alkhatib M, et al. Evaluating the adherence to guidelines for management of acute heart failure in the Gaza strip hospitals: a medical chart-based review study. Glob J Qual Saf Health 2019.

17. Alwali A, Ahmed M, Shaheen A. Prevalence and awareness about needle stick Injures among cleaners and healthcare providers in Gaza strip hospitals: a cross-sectional study. Lancet Palestinian Healthcare Alliance Conference March 2019, Amman, Jordan: Lancet Palestinian Healthcare Alliance, 2019.

18. Hamdan M, Alra'oof Saleem A. Changes in patient safety culture in Palestinian public hospitals: impact of quality and patient safety initiatives and programs. J Patiet Saf 2018;14:e67-73.

19. Leung GKK, Ang SBL, Lau TC, et al. Patient safety culture among medical students in Singapore and Hong Kong. Singapore Med J 2013;54:501-5

20. Ginsburg LR, Dhingra-Kumar N, Donaldson LJ. What stage are low-income and middle-income countries (LMICs) at with patient safety curriculum implementation and what are the barriers to implementation? A two-stage cross-sectional study. BMJ Open 2017;7:e016110.

21. World Health Organization. Patient safety curriculum guide: Multiprofessional edition. First ed, 2011.

22. Aljeesh YI, Alkariri N, Abusalem S, et al. Staff-Developed infection prevention program decreases health Care-Associated infection rates in pediatric critical care. J Nurs Care Qual 2015;30:71-6.

23. Abu-El-Noor NI, Hamdan MA, Abu-El-Noor MK, et al. Safety culture in neonatal intensive care units in the Gaza strip, Palestine: a need for policy change. J Pediatr Nurs 2017;33:76-82.

24. Hamdan M. Measuring safety culture in Palestinian neonatal intensive care units using the safety attitudes questionnaire. J Crit Care 2013;28:886.e7

25. Elmontsri M, Almashrafi A, Banarsee R, et al. Status of patient safety culture in Arab countries: a systematic review. BMJ Open 2017;7:e013487.

26. Lee $\mathrm{W}-\mathrm{C}$, Wung $\mathrm{H}-\mathrm{Y}$, Liao $\mathrm{H}-\mathrm{H}$, et al. Hospital safety culture in Taiwan: a nationwide survey using Chinese version safety attitude questionnaire. BMC Health Serv Res 2010;10.

27. Gabrani A, Hoxha A, Simaku A, et al. Application of the safety attitudes questionnaire (SAQ) in Albanian hospitals: a cross-sectional study. BMJ Open 2015;5:e006528.

28. Carruthers S, Lawton R, Sandars J, et al. Attitudes to patient safety amongst medical students and tutors: developing a reliable and valid measure. Med Teach 2009;31:e370-6.

29. Norman G. Likert scales, levels of measurement and the "laws" of statistics. Adv in Health Sci Educ 2010;15:625-32.

30. Carifio J, Perla R. Resolving the 50 -year debate around using and misusing Likert scales. Med Educ 2008;42:1150-2.

31. Brasaite I, Kaunonen M, Martinkenas A, et al. Health care professionals' attitudes regarding patient safety: cross-sectional survey. BMC Res Notes 2016;9:177.

32. Göras C, Unbeck M, Nilsson U, et al. Interprofessional team assessments of the patient safety climate in Swedish operating rooms: a cross-sectional survey. BMJ Open 2017;7:e015607.

33. Bari A, Jabeen U, Bano I, et al. Patient safety awareness among postgraduate students and nurses in a tertiary health care facility. Pak J Med Sci 2017;33.

34. Leonard M, Graham S, Bonacum D. The human factor: the critical importance of effective teamwork and communication in providing safe care. Qual Saf Health Care 2004;13 Suppl 1:i85-90.

35. Saberi M, Jamshidi E, Rajabi F, et al. Attitude of nurses toward the patient safety culture: a cross-sectional study of the hospitals in Tehran, Iran. Patient Saf Qual Improv 2017;5:554-60.

36. Lee H-Y, Hahm M-I, Lee SG. Undergraduate medical students' perceptions and intentions regarding patient safety during clinical clerkship. BMC Med Educ 2018;18.

37. Bridges D, Davidson RA, Soule Odegard P, et al. Interprofessional collaboration: three best practice models of interprofessional education. Med Educ Online 2011;16:6035.

38. Reeves S, Xyrichis A, Zwarenstein M, Teamwork ZM. Teamwork, collaboration, coordination, and networking: why we need to distinguish between different types of interprofessional practice. $J$ Interprof Care 2018;32:1-3.

39. Reiman T, Pietikäinen E, Oedewald P. Multilayered approach to patient safety culture. Qual Saf Health Care 2010;19:e20

40. Weller J, Boyd M, Cumin D, Teams CD. Teams, tribes and patient safety: overcoming barriers to effective teamwork in healthcare. Postgrad Med J 2014;90:149-54. 
41. Weller JM, Barrow M, Gasquoine S. Interprofessional collaboration among junior doctors and nurses in the hospital setting. Med Educ 2011;45:478-87.

42. Leonard M, Frankel A. How can leaders influence a safety culture? The Health Foundation, 2012.

43. Firth-Cozens J. Cultures for improving patient safety through learning: the role of teamwork. Qual Health Care 2001;10(Suppl 2):ii26-31.

44. Zimmo M, Laine K, Hassan S, et al. Differences in rates and odds for emergency caesarean section in six Palestinian hospitals: a population-based birth cohort study. BMJ Open 2018;8:e019509.

45. Elshami M, Alaloul E, Awadallah I, et al. Preventive intra-operative measures of surgical site infection (SSI) in the Gaza-Strip hospitals: a clinical audit. J Infect Prev 2017;18.

46. Harolds JA. Quality and safety in health care, part III: to err is human. Clin Nucl Med 2015;40:793-5.

47. Reason J. Human error: models and management. BMJ 2000;320:768-70.

48. Böttcher B, Abu-El-Noor N, Aldabbour B, et al. Maternal mortality in the Gaza strip: a look at causes and solutions. BMC Pregnancy Childbirth 2018;18:396.

49. García Elorrio E, Macchiavello D, Rodriguez V, et al. Knowledge, beliefs and attitudes report on patient care and safety in undergraduate students: validating the modified APSQ-III questionnaire. Medwave 2016;16:e6809-e09.

50. Li Y, Zhao Y. Hao Y, et al. perceptions of patient safety culture among healthcare employees in tertiary hospitals of Heilongjiang Province in northern China: a cross-sectional study. Int J Qual Health Care 2018.

51. Lei Z, Naveh E. Stuck between two lives: the paradox of eliminating and Welcoming errors. Am J Med Qual 2018;1:1-2.

52. Wu AW, Boyle DJ, Wallace G, et al. Disclosure of adverse events in the United States and Canada: an update, and a proposed framework for improvement. J Public Health Res 2013;2:e32
53. Elsous A, Akbari Sari A, AlJeesh Y, et al. Nursing perceptions of patient safety climate in the Gaza strip, Palestine. Int Nurs Rev 2017;64:446-54.

54. Kiesewetter I, Könings KD, Kager M, et al. Undergraduate medical students' behavioural intentions towards medical errors and how to handle them: a qualitative vignette study. BMJ Open 2018;8:e019500.

55. Alper E, Rosenberg El, O'Brien KE, O'Brien K, et al. Patient safety education at U.S. and Canadian medical schools: results from the 2006 clerkship directors in internal medicine survey. Acad Med 2009;84:1672-6.

56. Nabilou B, Feizi A, Seyedin H. Patient Safety in Medical Education: Students' Perceptions, Knowledge and Attitudes. PLoS One 2015;10:e0135610-8.

57. Liao JM, Thomas EJ, Bell SK. Speaking up about the dangers of the hidden curriculum. Health Aff 2014;33:168-71.

58. Mahood S. Beware the hidden curriculum. Med Educ 2011;57:983-5

59. Gaupp R, Fabry G, Körner M. Self-Regulated learning and critical reflection in an e-learning on patient safety for third-year medical students. Int J Med Educ 2018;9:189-94.

60. Wetzel AP, Dow AW, Mazmanian PE. Patient safety attitudes and behaviors of graduating medical students. Eval Health Prof 2012;35:221-38.

61. Azimi L, Tabibi S, Maleki M, et al. Influence of training on patient safety culture: a nurse attitude improvement perspective. Int $J$ Hosp Res 2012;1:51-6.

62. Eltony S, El-Sayed N, El-Araby S, et al. Implementation and evaluation of a patient safety course in a problem-based learning program. Educ Health 2017;1.

63. Kow AWC, Ang BLS, Chong CS, et al. Innovative patient safety curriculum using iPAD game (passed) improved patient safety concepts in undergraduate medical students. World J Surg 2016;40:2571-80.

64. Irvine $\mathrm{AB}$, Bourgeois $\mathrm{M}$, Billow $\mathrm{M}$, et al. Internet training for nurse aides to prevent resident aggression. J Am Med Dir Assoc 2007;8:519-26. 